\title{
$\cdot \nabla$ \\ IJCRR \\ Section: Healthcare \\ A Digital Cephalometric Study to Evaluate the Effect of Age in Relating the Level of Ala Tragal Line to the Occlusal Plane
}

Sci. Journal Impact

Factor: 6.1 (2018)

ICV: 90.90 (2018)

\author{
Lambodaran G1, Jagadesaan N ${ }^{2}$, Peter John ${ }^{3}$, S. A. Mohamed Ali ${ }^{4}$ \\ 'Associate Professor, Department of Prosthodontics \& Implantology, Meenakshi Ammal Dental College, Chennai 95, India; \\ ${ }^{2}$ Associate Professor, Department of Prosthodontics \& Implantology, JKKN Dental College and Hospial, Kumarapalayam, Namakkal, \\ 638183, India; ${ }^{3}$ Associate Professor, Department of Prosthodontics \& Implantology, SRM Dental College and Hospital, Ramapuram, \\ Chennai, India; 4 Prosthodontist \& Implantologist, Almana General Hospital, Al Khobar-Saudi Arabia.
}

\section{ABSTRACT}

Aim of the study: To evaluate the influence of age on the levels of ala tragal line concerning the occlusal plane in south Indian population.

Materials and Method: In this cross-sectional study, a total of 100 Subjects were divided into two groups with each group having 50 subjects ( 25 male \& 25 Female) based on their age, Group A 20 to 35 years and Group B 36 to 50 years of age with angles class I malocclusion. The radio-opaque markers (lead balls) were then placed about superior tragus, middle tragus, inferior tragus and ala of the nose. Following this, a lateral cephalogram was made and the corresponding angles, from ala $(A)$ to the superior margin of the tragus (ST), ala (A) to the middle margin of the tragus (MT), From ala (A) to the inferior margin of the tragus (IT) were measured using Facad software and the results were statistically analysed.

Results: The results of the study showed that the mean angle of IT (group A - 2.990; group B - 3.240) the line from the ala of the nose to the tragus of the ear was found to be the lowest in both the groups and was almost parallel to the occlusal plane in both the groups. On Statistical analysis, the mean difference was found to be almost similar in both the groups and there was no statistically significant difference between the two groups $\mathrm{P}>0.05$.

Conclusion: The line running from the ala of the nose to the inferior part of the tragus of the ear is more parallel to the occlusal plane in south Indian population irrespective of the age group.

Key Words: Ala tragal line, Occlusal plane, Facade software, The effect of age, Digital cephalometry

\section{INTRODUCTION}

The complete denture treatment prosthodontics is one of the commonest modalities of restoring a completely edentulous patient and also many elderly patients seek this treatment modality in a developing country like india ${ }^{1}$. The two primary objectives of any prosthodontic procedure are to restore function and esthetics. To achieve the same, various steps are involved in the fabrication of complete denture. One of the primary factors in achieving this biofunctional harmony in complete denture is to precisely place the prosthetic teeth in the same position as previously occupied by the natural set of teeth and this is attained by the proper orientation of occlusal plane ${ }^{2}$.
The occlusal plane can be defined as "the average plane established by the incisal and occlusal surfaces of the teeth. Generally, it is not a plane but represents the planar mean of the curvature of these surfaces ${ }^{3}$ ". The orientation of the occlusal plane plays a pivotal role in establishing a mechanically balanced articulation ${ }^{4}$. Though there are several methods demonstrated in the literature for orientation of the occlusal plane, the use of camper's plane (ala tragal line) is the most common method in achieving the same ${ }^{5}$. Campers plane can be defined as the line that runs from the inferior border of the ala of the nose to the tip of the tragus ${ }^{3}$.

Despite it being the most commonly used method in occlusal plane orientation there has been varied thoughts from various authors and also previous studies in the literature regard-

\section{Corresponding Author:}

G. Lambodaran, Flat 2f, Block 1, Ceebros park, 2A Radhakrishnan Salai, Valasaravakkam, Chennai-87, India. Ph: 91 9894946334; E-mail: lambod5@gmail.com

ISSN: 2231-2196 (Print)

Received: 07.07 .2020
ISSN: 0975-5241 (Online)

Revised: 18.08 .2020
Accepted: 23.09 .2020
Published: 06.10 .2020 
ing the posterior reference end of ala tragus line concerning superior, middle and inferior tragus of the ear. Winkler ${ }^{6}$, heartwe $11^{7}$ and Boucher ${ }^{8}$ advocated that it should correspond to the superior border of the tragus. Neil and Narin advocated that it should correspond to the centre of the tragus. While Zarb and Bolender ${ }^{9}$ did not specify the part of the tragus determining the posterior reference end of the ala tragal line. The studies of Rostamkhani et al. ${ }^{10}$, Sharifi et al. ${ }^{11}$ Nayar et al. ${ }^{12}$ indicated that the inferior part of the tragus should bewtaken as the posterior reference end of ala tragal line. While the studies of Shigli et al. ${ }^{13}$ and Nissanet al..${ }^{14}$ demonstrated that the line passing through superior and middle border of the tragus were parallel to the occlusal Plane and these studies did not specify on the influence of age in the level of ala tragal line.

Thus as per the current literature reports it is clear that the use of ala tragus line for occlusal plane orientation has been a topic of debate over the past many years. This is because various authors have cannot come to a consensus as to which posterior tragal reference end should be used for occlusal plane orientation. Though there have been various factor such as race, ethnicity, type of population ${ }^{15,16}$ said to influence the position ala tragal line, there is not much light and not much of studies on the effect of age on level of ala tragal line. With this objective in mind this study was done to evaluate the influence of age on the levels of ala tragal line about the occlusal plane.

\section{MATERIALS AND METHOD}

In this cross-sectional study, a total of 100 Subjects from south Indian population were evaluated. The subjects were divided into two groups with each group having 50 subjects ( 25 male \& 25 Female) based on their age, Group A 20 to 35 years and Group B 36 to 50 years of age. The inclusion criteria were, the Subjects should have

- complete set of natural teeth excluding the third molar

- Normal overjet and overbite

- class I molar relationship

The exclusion criteria were

- Orthodontically treated patients

- Missing teeth

- Any artificial crowns and bridges

- Drifting or supra eruption

Following the selection of the subjects based on the abovementioned criteria, four markings were done on the subjects in the following regions for the placement of radio-opaque markers corresponding to the superior(ST), middle (MT), inferior part of the tragus(IT) and the ala of the nose(AL). The radio-opaque markers (lead balls) were then placed in that marked position as shown in Fig 1 and a lateral cephalogram was made as shown in Fig 2. The lateral cephalograms were then evaluated using FACAD SOFTWARE. This software was programmed in such a way that, the digital software reads the marked points and measures the corresponding angle to the occlusal plane Fig 3. The following angles were measured for each individual

From ala (A) to the superior margin of the tragus (ST)

From ala (A) to the middle margin of the tragus (MT)

From ala (A) to the inferior margin of the tragus (IT)

\section{Statistical Analysis}

The results were then Stastisticallyanalaysed using Pearson correlation coefficient to compare the significance among the different variables in both the groups. Independent sample t-test was done to find out the significance among the variables between two groups with the level of significance as $\mathrm{P}<0.05$.

\section{RESULTS}

The data obtained from the digital software revealed that the line joining ala to the inferior border (IT) of the tragus was closest to the occlusal plane, in 90 of the total (Group A - 47, Group B -43) subjects, while 7 of the study subjects exhibited the occlusal plane to be parallel to the line joining the ala to the middle border (MT) of the tragus. Only 3 of the study subjects exhibited occlusal plane to be parallel to line from the ala to the superior border of tragus as shown in figure 4 .

The mean angles measured by the façad software are listed in (Table 1,2) for both the groups A and B. The results of the study showed that the mean angle of IT (group A - 2.99; group $\mathrm{B}-3.24)$ the line from the ala of the nose to the tragus of the ear was found to be the lowest in both the groups (figure 5) and was almost parallel to the occlusal plane in both the groups.

\section{Statistical Results}

The results were then Stastisticallyanalaysed using Pearson correlation coefficient (Table 3,4) to compare the significance among the different variables in both the groups. In both, the groups the P-value of IT line was not found to be statistically significant, since $\mathrm{P}$-value is $\mathrm{P}>0.05$ ( group A 0.25 , group $B 0.24$ ). This clearly shows that IT seems to be a precise factor in both the groups compared to ST and MT.

Independent sample t-test was done to find out the significance among the variables between two groups (Table 5). In both the groups, the mean difference was found to be almost similar and the $\mathrm{p}$ values were found to be not significant $\mathrm{P}>0.05$. This indicates that the age does not tend to influence the relation between ala tragal line and occlusal plane. 


\section{DISCUSSION}

In the fabrication of complete dentures, the orientation of the occlusal plane plays a critical role in the successful prognosis of the prosthesis ${ }^{17}$. One of the challenging task for the dentist in occlusal plane orientation in complete denture is to relocate the occlusal plane in the same position in which it existed previously. This Precise orientation is essential for the harmonious function of the stomatognathic system ${ }^{4,18}$. Though there are several reference planes and landmarks have been suggested in the literature for occlusal plane orientation, the Campers plane is the most commonly used reference plane.

Despite it being widely used, there are a lot of controversies and varied thoughts regarding the posterior reference end of the ala tragal line in the literature till date and also there is not much of data on the influence of age on the positional variation of the ala tragal line. Hence this study was done to find out the effect of age on the relation of ala tragal line to the occlusal plane.

This study comprises of two groups with each group having 50 subjects. The age of the subjects representing the group was group A 20 to 35 years, group B 36 to 50 years. This age group interval was based on the age group classification by Jana $\mathrm{R}$ et al.$^{19,20}$ in which we have opted for the young adult group which is between 20-35 years and middle age group 36 to 50 years. These two age groups were taken into consideration since age-related soft tissue changes that are taking place may affect the level of Ala-Tragus line. Besides these, by around 20 years there will be the cessation of facial growth and the upper age limit was kept 50 years so that the dentition could be expected to remain normal without much tooth loss and attrition. ${ }^{21}$

In analysing the validity of reference points used to locate the occlusal plane, the manual cephalometrics is the most common method used in previous studies. Since it is prone to subjective variation and also will become a limitation, in this study we have used digital cephalometrics using the Facad software to overcome that limitation. This software which is extensively used in the field of orthodontics has various advantages such as precision, less time consuming, image enhancement and more reliability of the measurements compared to manual tracing. ${ }^{22,23}$

The results of this study clearly showed that the age factor does not tend to influence the relation between ala tragal line and occlusal plane. The inferior tragal line IT that runs from the inferior part of the tragus to the ala of the nose was almost parallel to the occlusal plane in both Group A and B. The results of this study was in correlation with the study done by mainakkantisaha et al ${ }^{24}$ in a specified type of population, which also showed that age does not influence the relation between ala tral line and the occlusal plane.
Among the three different posterior reference ends of the ala tragal line, the inferior tragus was found to be almost parallel to the occlusal plane in both the age groups. These results were following the results of the various previous studies of Karkazis and Polyzois ${ }^{25}$, Van Niekerk et al. ${ }^{26}$ Rostamkhani et al. ${ }^{10}$, Sharifi et al. ${ }^{11}$ Nayar et al. ${ }^{12}$ Chaturvedi et al. ${ }^{15}$ on the ala tragal line which showed similar results.

Contrary to this result, the studies of Al Quran et al., ${ }^{27}$ Gupta and Singh, ${ }^{28}$ Sadr and Sadr, ${ }^{29}$ demonstrated that the line passing through superior and middle border of the tragus were parallel to the Occlusal Plane. The difference in these results can be attributed to factors such as type of population, race and their ethinicity. ${ }^{15,16}$

The current study had certain limitations which includes: a specific group of the population only was studied, only angle class 1 malocclusion was taken into consideration.

\section{CONCLUSION}

This study was done to identify the precise anatomical landmarks to be used in establishing the occlusal plane in fabricating various types of the prosthesis to achieve esthetics and functional harmony and also the impact of age on these landmarks were analysed. Within the limitations of the study, it can be concluded that

1. The line running from the ala of the nose to the inferior part of tragus of the ear is more parallel to the occlusal plane in south Indian population irrespective of the age group.

2. There is no definite relationship exists between the age factor and the level of ala tragal line.

3. The inferior part of the tragus can be used as the posterior end of ala tragal line for occlusal plane orientation in prosthesis fabrication in south Indian population.

\section{Acknowledgements: NIL}

\section{Conflict of interest: NIL}

\section{Funding Details: NIL}

\section{REFERENCES}

1. Anupuma Prasad, ChetanHegde, Krishna Prasad D. A Study to Evaluate and Compare Oral stereognosis ability and oral tactile sensibility of satisfied and dissatisfied subjects wearing complete denture prosthesis.IJCRR .2020;4(6):139-145.

2. LammieGA. Full dentures, Oxford, 1956. Blackwell Scientific Publications. Pp.118-122.

3. Glossary of prosthodontic terms. J Prosthet Dent. 2005;94:1092.

4. Williams DR. Occlusal plane orientation in complete denture construction. J Dent. 1982;10(4):311-316.

5. Shetty S, Zargar Nm, Shenoy K, RekhaV .Occlusal plane evaluation in edentuluouspateints :A review. J Indian Prosthodontic society $2013 ; 13: 142-8$. 
6. Winkler S. Essentials of Complete Denture Prosthodontics, 2nd ed. St. Louis: Mosby year-book; 1998:140.

7. Rahn AO, Heartwell CM. Textbook of Complete Denture,5th ed. Philadelphia: Lea \& Febiger;2002:270.

8. Boucher CO. Current clinical dental terminology. 3rd ed. St.Louis: Mosby, 1982:175.

9. Zarb GA, Bolender CL. Prosthodontic Treatment for Edentulous Patients: Complete Dentures and Implant-Supported Prostheses, 12th ed. St. Louis: Mosby; 2004:262.

10. Rostamkhani F, Sahafian A, Kermani H. A cephalometric study on the relationship between the occlusal plane, ala-tragus and Camper's lines, in patients with Angle's Class III Malocclusion. J Dent Tehran Univ Med Sci. 2005;2(2):46-49.

11. Sharifi E, Rostamkhani F. A cephalometric study on the relationship between occlusal plane and ala-tragus and Campers plane. J Mashhad Dent Sch. 2001;24(324):112-115.

12. Nayar S, Bhuminathan S, Bhat WM, Mahadevan R. Relationship between occlusal plane and ala-tragus line in dentate individuals: A Clinical pilot study. J Pharm BioalliedSci 2015;7Suppl 1:95-97.

13. Shigli K, Chetal B, Jabade J. Validity of soft tissue landmarks in determining the occlusal plane. J Indian ProsthodontSoc 2005;5:139.

14. Nissan J, Barnea E, Zeltzer C, CardCash HS. Relationship between occlusal plane determinants and craniofacial structures. J Oral Rehabil 2003;30:587-91.

15. Chaturvedi S, Thombare R. Cephalometrically assessing the validity of superior, middle and inferior tragus points on the alatragus line while establishing the occlusal plane in an edentulous patient. J AdvProsthodont. 2013;5:58-66.

16. Amit D. Hindocha, Vikas N. Vartak, Aruna J. Bhandari, Mohit Dudani: A Cephalometric Study to Determine the Plane of Occlusion in Completely Edentulous Patients: Part I. J Indian Prosthodontic Society, 2010;10:203-207.

17. Celebic A, Valentic-Peruzovic M, Kralijevic K, Brkic H. A study of the occlusal plane orientation by the intra-oral method. J Oral Rehabilitation. 1995;22:233-236.

18. Monteith BD. A cephalometrically programmed adjustable plane: a new concept in occlusal plane orientation for complete denture patients. J Prosthet Dent. 1985;54: 388-392.
19. Jana R, Pal H, Chowdhury AR. Age Group Estimation Using Face Angle. IOSRJCE. 2012;(5):35-39.

20. Jana R, Datta D, Saha R. Age Group Estimation using Face Features. IJEIT. 2013;3(2):130-34.

21. Kumar S, Garg S, Seema Gupta. A determination of occlusal plane comparing different levels of the tragus to form an alatragal line or Camper's line: A photographic study. J AdvProsthodont 2013;5:9-15.

22. Mohammed Umar Farooq, Mohd. Abdullah Khan. Assesing the reliability of digitalised cephalometric analysis in comparison with manual cephalometric analysis. Journal of clinical and diagnostic research 2016; 10: 20-23

23. MK Kamath, AV Arun. Comparison of cephalometric readings between manual tracing and digital software tracing: A Pilot Study. International journal of orthodontic rehabilitation 2016;7:135-8.

24. Mainak KantiSaha, Purvi Dhariwal, Vinod V, Anurag Jindal, Mahendra Dave, Prerna Agrawal. A comparative evaluation of the parallelism of the occlusal plane with different levels of the tragus forming the ala-tragal line in Indore-Malwa dentate population - A Photographic study. Journal of Applied Dental and Medical Sciences 2017;3(2):120-124

25. Karkazis HC, Polyzois GL, Zissis AJ. Relationship between the ala-tragus line and natural occlusal plane implication in denture prosthodontics. Quintessence Intl. 1986;17(4):253-257.

26. Van Niekerk FW, Miller VJ, Bibby RE. Ala tragus line in complete denture prosthetics. J Prosthet Dent. 1985;53(1):67-70.

27. Al Quran FA, Hazza'a A, Al Nahass N. The position of the occlusal plane in natural and artificial dentitions as related to other craniofacial planes. J Prosthodont 2010;19:601-5.

28. Gupta R, Aeran H, Singh S. Relationship of anatomic landmarks with occlusal plane. J Indian Prosthodontic Society 2009; 9:142145.

29. Sadr K, Sadr M. A study of parallelism of the occlusal plane and ala-tragus line. J Dent Res Dent Clin Dent Prospects 2009;3:107-9.

Table 1: Mean angle values of ST, MT, IT of Group A.

\begin{tabular}{lccccccc} 
Grouping Variables & $\begin{array}{c}\text { Mean in } \\
\text { degrees }\end{array}$ & Std. Deviation & Range & Min & Max & Variance & N \\
ST to OL ST & 5.402 & .4653 & 2.1 & 4.2 & 6.3 & .217 & 50 \\
MT to OL MT & 4.164 & .5795 & 2.1 & 3.1 & 5.2 & .336 & 50 \\
IT- to OL IT & 2.994 & .8311 & 2.6 & 1.7 & 4.3 & .691 & 50 \\
\hline
\end{tabular}

Table 2: Mean angle values of ST, MT, IT of Group B.

\begin{tabular}{lccccccc} 
Grouping Variables & Mean in degrees & Std.Deviation & Range & Min & Max & Variance & N \\
ST to OL ST & 5.874 & .5785 & 2.7 & 4.2 & 6.9 & .335 & 50 \\
MT to OL MT & 4.498 & .6514 & 2.7 & 3.1 & 5.8 & .424 & 50 \\
IT- to OL IT & 3.242 & .7928 & 2.9 & 1.9 & 4.8 & .629 & 50 \\
\hline
\end{tabular}


Table 3: Pearson correlation coefficient value of Group A.

\begin{tabular}{|c|c|c|c|}
\hline \multicolumn{4}{|c|}{ Correlations } \\
\hline Grouping Variables & $\mathbf{N}$ & Pearson Correlation & p-value \\
\hline $\begin{array}{l}\text { ST to OL } \\
\text { ST }\end{array}$ & 50 & 0.719 & 0.000 \\
\hline $\begin{array}{l}\text { MT to OL } \\
\text { MT }\end{array}$ & 50 & 0.527 & 0.000 \\
\hline $\begin{array}{l}\text { IT to OL } \\
\text { IT }\end{array}$ & 50 & 0.316 & 0.25 \\
\hline
\end{tabular}

Correlation is significant at the 0.05 level (2-tailed).

Table 4: Pearson correlation coefficient value of Group B.

\begin{tabular}{|c|c|c|c|}
\hline \multicolumn{4}{|c|}{ Correlations } \\
\hline Grouping Variables & $\mathbf{N}$ & Pearson Correlation & p-value \\
\hline $\begin{array}{l}\text { ST to OL } \\
\text { ST }\end{array}$ & 50 & 0.721 & 0.000 \\
\hline $\begin{array}{l}\text { MT to OL } \\
\text { MT }\end{array}$ & 50 & 0.619 & 0.000 \\
\hline $\begin{array}{l}\text { IT to OL } \\
\text { IT }\end{array}$ & 50 & 0.320 & 0.24 \\
\hline
\end{tabular}

Correlation is significant at the 0.05 level (2-tailed).

Table 5: Independent sample t-test comparing Group A and Group B.

\begin{tabular}{|c|c|c|c|c|c|c|c|c|c|c|}
\hline \multicolumn{11}{|c|}{ Independent Sample t-Test } \\
\hline & Group & $\mathbf{N}$ & Mean & S.D & S.E & Mean Difference & $\mathbf{F}$ & p-value & $\mathbf{T}$ & p-value \\
\hline \multirow[t]{2}{*}{$\mathrm{X}$} & A & 50 & 4.187 & .523 & .074 & -.3153 & .108 & .743 & -3.22 & .082 \\
\hline & B & 50 & $4 \cdot 538$ & .567 & .080 & -.3355 & & & & \\
\hline
\end{tabular}

X: ST to OL, MT to OL \& IT to OL;

A: $20-35$ years, B: $36-50$ years

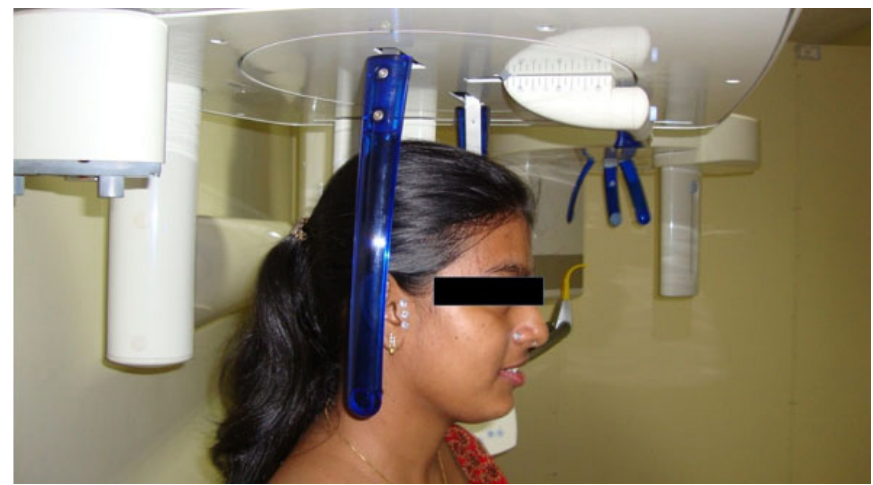

Figure 1: Placement of radio-opaque markers.

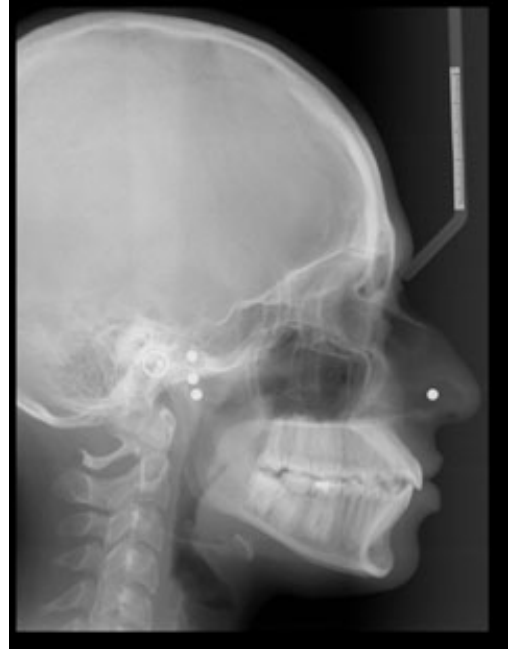

Figure 2: Lateral cephalogram with radio-opaque markers. 


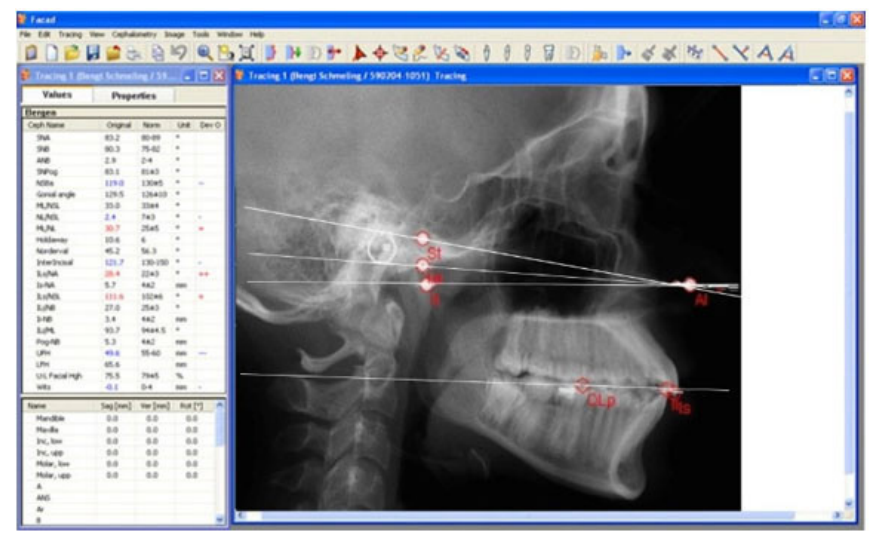

Figure 3: Analysis using Facad Software.

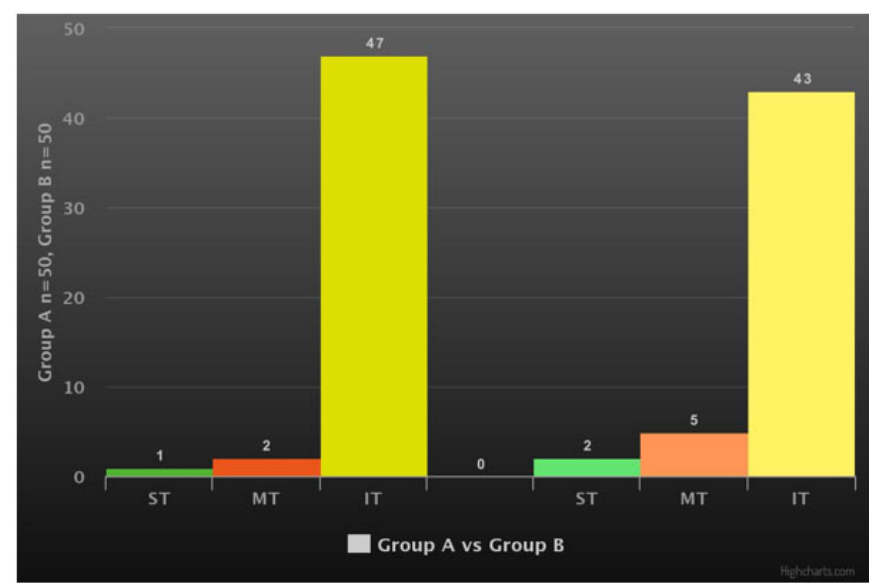

Figure 4: Results showing the Façad software analysis of Group A and Group B.

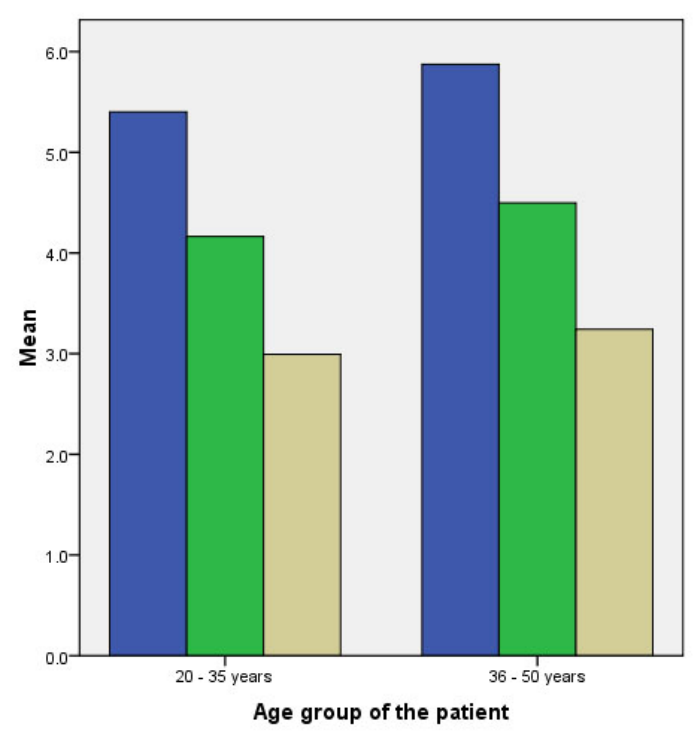
Figure 5: Mean value angles of Group A and Group B.

DST-AL to OL MMT_AL to OL 